\title{
LORAZEPAM AS ANXIOLYTIC SEDATIVE NIGHT BEFORE OPERATION
}

\author{
Karim $\mathrm{ME}^{1}$, Rahman $\mathrm{MH}^{2}$, Hossain $\mathrm{MHMD}^{3}$, Ahsan $\mathrm{MN}^{4}$
}

\begin{abstract}
Introduction: Surgical patients have a high incidence of anxiety and there is a significant inverse relationship between anxiety and smoothness in induction of anaesthesia. The benzodiazepines are very effective at melting away the active terror of anxiety. Diazepam, a long acting benzodiazepine, is widely used by the anaesthesiologist to allay anxiety and provide sedation. The metabolism of diazepam is slow and is depressed by many factors such as old age, disease states (e.g. hepatic cirrhosis) and concomitant drug administration (e.g. cimetidine). Lorazepam, an intermediate acting benzodiazepine, is well absorbed orally. It is conjugated in the liver to the pharmacologically inactive glucuronide and its metabolism is less impaired by the above factors.
\end{abstract}

Objective: To compare the anxiolytic properties of lorazepam with diazepam before elective surgical procedures.

Method: One hundred patients of American Society of Anaesthesiologists (ASA) grade I and grade II, who were scheduled for general surgical, gynaecological operative procedures under general and regional anaesthesia in Combined Military Hospital, Saidpur Cantonment, during the period between June 2008 to June 2010, were included in this study. They were randomly distributed into two groups. Subjects of group $A(n=50)$ received diazepam (Sedil) orally in a dose of $5 \mathrm{mg}$ for $<30 \mathrm{~kg}$ body weight or $10 \mathrm{mg}$ for $30-70 \mathrm{~kg}$ body weight or $15 \mathrm{mg}$ for $>70 \mathrm{~kg}$ body weight. Subjects of group $B(n=50)$ received lorazepam (Ativan) orally in a dose of $2 \mathrm{mg}$ for $<30 \mathrm{~kg}$ body weight or $4 \mathrm{mg}$ for $30-70 \mathrm{~kg}$ body weight or $6 \mathrm{mg}$ for $>70 \mathrm{~kg}$ body weight. The effects of the two drugs as anxiolytic sedatives were compared on the basis of haemodynamic parameters, side effects and quality of sleep.

Results: There was no significant change in haemodynamic parameters between the two groups. Drugs on group B (Lorazepam group) were found to be more anxiolytic than drugs on group A (Diazepam group). Twenty percent of patients in diazepam group complained of moderate anxiety but it was absent in lorazepam group $(\mathbf{p}<\mathbf{0 . 0 1})$. Six percent of patients were restless/agitated in preoperative period in diazepam group, but it was absent in lorazepam group. Percentage of tranquil patients was significantly higher in lorazepam group $(44 \%)$ than that in diazepam group $(30 \%)$. Hangover effect was noted markedly in group B patients $(44 \%)$ which was nil in group A patients $(p<0.01)$, but it was beneficial for induction of anaesthesia. Moreover this hangover effect was significantly higher $(p<0.01)$ in female population $(50 \%)$ than in male population $(\mathbf{2 1 . 0 5 \%})$. Some other side effects like nausea, vertigo were also noticed in patients of both groups and females were more susceptible to these side effects than males which might be an individual variation.

Conclusion: Considering all the factors, lorazepam appeared to be a better option than diazepam as anxiolytic sedative night before operation.

Keywords: Lorazepam, diazepam, anxiolytic sedative, before operation

\section{Introduction}

One major benefit of a preoperative assessment clinic is to reduce patient anxiety. There are many reasons of pre operative anxiety, fear of the unknown or of post operative nausea and pain, fear of loss of control during anaesthesia, fear based on previous experience or the experience of others, of being asleep during surgery ${ }^{1-3}$. When medication is the treatment of choice to reduce anxiety, the benzodiazepines are the drugs routinely used. Diazepam which is available in tablet and intravenous form is a popular drug for reduction of preoperative anxiety, specially when patient can be treated earlier than one day before surgery. The prolonged action of diazepam is attributable not only to its excretion half life (20-40 hours) but also to the long half life of its metabolites. Orally administered diazepam is well absorbed from the intestine and plasma level peak after 60 minutes $^{1,2}$. Lorazepam is approximately 4 times as potent as diazepam. A dose of $2.5 \mathrm{mg}$ of orally administered lorazepam is equivalent to $10 \mathrm{mg}$ of diazepam. Onset of action of lorazepam is slower, peak drug effect does not occur for 40 minutes after intravenous injection. Duration of action is approximately 3-4 times greater than that of diazepam, but shorter mean elimination half life(10-14hours) and fewer venous sequelae results from lorazepam than with diazepam $^{2,3}$.

\section{Materials and Methods}

One hundred patients of American Society of Anaesthesiologists (ASA) grade I and grade II, who were

1. Lt Col Md Enayet Karim MBBS, DA, FCPS, Graded Specialist in Anaesthesiology. CMH Saidpur; 2. Lt Col Md Hamidur Rahman (Rtd) MBBS, FCPS, Senior Consultant and Head of Cardiac Anaesthesiology, Ibrahim Cardiac Hospital and Research Institute. Dhaka; 3. Brig Gen MHM Delwar Hossain MBBS, DA, FCPS, Professor of Anaesthesiology, Armed Forces Medical College, Dhaka Cantonment; 4. Brig Gen Md Nazmul Ahsan MBBS, FCPS, Adviser Specialist in Anaesthesiology, Combined Military Hospital, Dhaka Cantonment. 
scheduled for general surgical and gynaecological procedures on routine basis under general or regional anaesthesia were included in this study. The patients were randomly divided into two groups; group $A(n=50)$ and group $B(n=50)$. Group A patients received Tab Diazepam (Sedil), $5 \mathrm{mg}$ (below $30 \mathrm{~kg}$ body weight), 10mg (30-70 $\mathrm{kg}$ body weight), $15 \mathrm{mg}$ (above $70 \mathrm{~kg}$ body weight), at 2200 hours night before operation day. Group B patients received Tab Lorazepam (Ativan), 2 $\mathrm{mg}$ (below $30 \mathrm{~kg}$ body weight), $4 \mathrm{mg}$ (30-70 kg ), $6 \mathrm{mg}$ (above $70 \mathrm{~kg}$ body weight), at 2200 hours night before operation day. The base line haemodynamic parameters e.g. pulse, blood pressure (BP), were recorded before giving the sedative at night and in the morning at 0600 hours. The patient, attendant and the medical staff were asked regarding the sedation at night, whether he/she had good sleep or not. Any complication or side effects e.g. nausea, vomiting, vertigo etc were recorded in the morning of operation day. Children below 12 years, old patients above 65 years, obstetric patients and those who were sensitive to those drugs were excluded from this study.

Anxiety was subjectively scored by the patient in the morning of the day of operation on a linear scale from 0 to 5 , where 0 reflects no anxiety and 5 reflects maximum anxiety. Quality of sedation was objectively scored by the investigator on a linear scale from 0 to 5 , where 0 reflects anxiety or agitation and 5 reflects excellent sleep. For statistical analysis, student's ' $t$ ' test, analysis of variance (ANOVA) and chi-square test were used where appropriate. Results were expressed as mean $\pm \mathrm{SD}$ and categorical data in percentage (\%) and frequency (f) as appropriate. Differences were considered statistically significant if $p<0.05$.

\section{Results}

Pulse and blood pressure were recorded at 2200 hours on the day before operation and at 0600 hours on the day of operation. Demographic data and haemodynamic parameters are shown in Tablel I and Table II. Difference of change in systolic (SBP) and diastolic (DBP) blood pressures and pulse rate at 2200 hours and 0600 hours between group A and group B were not statistically significant ( $\mathrm{p}>0.05)$.

Table-I: Demographic Data

\begin{tabular}{|l|c|c|}
\hline & Group A & Group B \\
\hline Age(in year) & $35.0 \pm 3.2$ & $38.0 \pm 2.4$ \\
\hline Weight(in kg) & $56.1 \pm 2.1$ & $58.2 \pm 2.6$ \\
\hline Male/Female & $35 / 15$ & $38 / 12$ \\
\hline
\end{tabular}

Table-II: Haemodynamic parameters of two groups

\begin{tabular}{|l|c|c|c|c|}
\hline \multirow{2}{*}{} & \multicolumn{2}{|c|}{ Group A } & \multicolumn{2}{c|}{ Group B } \\
\cline { 2 - 5 } & $\begin{array}{c}2200 \\
\text { hours }\end{array}$ & $\begin{array}{c}0600 \\
\text { hours }\end{array}$ & $\begin{array}{c}2200 \\
\text { hours }\end{array}$ & $\begin{array}{c}0600 \\
\text { hours }\end{array}$ \\
\hline SBP (mm of Hg) & $114 \pm 2.5$ & $110 \pm 2.4$ & $116 \pm 2.4$ & $112 \pm 2.2$ \\
\hline DBP (mm of Hg) & $73 \pm 2.5$ & $70 \pm 1.8$ & $74 \pm 1.8$ & $69 \pm 2.1$ \\
\hline Pulse rate (/min) & $76 \pm 3.8$ & $70 \pm 2.4$ & $77 \pm 2.3$ & $68 \pm 3.2$ \\
\hline
\end{tabular}

* $\mathrm{p}>0.05$
Table III and Table IV are showing quality of sleep after medication between the two groups. It was found that group B patients had better quality of sleep than group A patients, although no patient suffered sleepless night among the two groups. Group A patients were associated with higher anxiety scores than group B patients $(\mathrm{p}<0.01)$. On the other hand, sedation scores were greater in the group B patients than group A patients $(\mathrm{p}<0.01)$. Table V and Table VI show the sex distribution of the side effects and future option for anxiolysis between the two groups. It was found that female population suffered mostly ( $<<0.01)$, specially hangover effects.

Table-III: Distribution of cases as per anxiety level and scores

\begin{tabular}{|l|l|l|}
\hline Grade & $\begin{array}{l}\text { Group-A } \\
(\mathbf{n = 5 0 )}\end{array}$ & $\begin{array}{l}\text { Group-B } \\
(\mathbf{n = 5 0 )}\end{array}$ \\
\hline No anxiety-0 [f(\%)] & 00 & $07(14 \%)$ \\
\hline Mild- (1-2) [f(\%)] & $40(80)$ & $43(86 \%)$ \\
\hline Moderate-(3-4) [f(\%)] & $10(20)$ & 00 \\
\hline Severe- 5 [f(\%)] & 00 & 00 \\
\hline Anxiety scores & $4.8 \pm 0.3$ & $3.9 \pm 0.3$ \\
\hline
\end{tabular}

Table-IV: Distribution of cases as per sedation level and scores

\begin{tabular}{|l|l|l|}
\hline Grade & $\begin{array}{l}\text { Group-A } \\
(\mathrm{n}=50)\end{array}$ & $\begin{array}{l}\text { Group-B } \\
(\mathrm{n}=50)\end{array}$ \\
\hline Agitated/restless [f(\%)] & $03(06)$ & 00 \\
\hline Awake, cooperative [f(\%)] & $32(64)$ & $14(28)$ \\
\hline Tranquil [f(\%)] & $15(30)$ & $22(44)$ \\
\hline Drowsy [f(\%)] & 00 & $10(20)$ \\
\hline $\begin{array}{l}\text { Asleep, rouses rapidly } \\
\text { to command [f(\%)] }\end{array}$ & 00 & $04(08)$ \\
\hline Sedation scores & $3.5 \pm 0.2$ & $4.2 \pm 0.1$ \\
\hline
\end{tabular}

Table-V: Frequency distribution of side effects

\begin{tabular}{|l|l|l|l|l|}
\hline \multirow{2}{*}{ Side effects } & \multicolumn{2}{|c|}{ Group-A } & \multicolumn{2}{c|}{ Group-B } \\
\cline { 2 - 5 } & $\begin{array}{l}\text { Male } \\
(\mathbf{n = 3 5 )}\end{array}$ & $\begin{array}{l}\text { Female } \\
(\mathbf{n = 1 5})\end{array}$ & $\begin{array}{l}\text { Male } \\
(\mathbf{n = 3 8})\end{array}$ & $\begin{array}{l}\text { Female } \\
(\mathbf{n = 1 2})\end{array}$ \\
\hline $\begin{array}{l}\text { Hangover } \\
\text { effect [f (\%)] }\end{array}$ & 00 & 00 & $08(21.05)$ & $06(50)$ \\
\hline Nausea [f (\%)] & 00 & $01(6.66)$ & $01(2.63)$ & $01(08.33)$ \\
\hline Vomiting [f(\%)] & 00 & 00 & 00 & 00 \\
\hline Vertigo [f(\%)] & 00 & $02(13.33)$ & $01(2.63)$ & $01(08.33)$ \\
\hline $\begin{array}{l}\text { No side effects } \\
\text { [f (\%)] }\end{array}$ & $35(100 \%)$ & $12(80)$ & $28(73.68)$ & $04(33.33)$ \\
\hline
\end{tabular}

$\mathrm{p}<0.01$ (calculated between the incidence of hangover effect and nausea between male and female in group B patients).

Table-VI: Patients' option for anxiolysis and sedation with same medication in future

\begin{tabular}{|l|l|l|l|}
\hline Group & $\begin{array}{l}\text { Preferred } \\
\text { f }(\mathbf{\%})\end{array}$ & $\begin{array}{l}\text { Not preferred } \\
\text { f }(\%)\end{array}$ & $\begin{array}{l}\text { No option } \\
\text { f (\%) }\end{array}$ \\
\hline Group A (n=50) & $30(60)$ & $08(16)$ & $12(24)$ \\
\hline Group B (n=50) & $40(80)$ & $05(10)$ & $05(10)$ \\
\hline
\end{tabular}




\section{Discussion}

High level of preoperative anxiety frequently occurs in patients undergoing surgical procedures. Reduction of anxiety has a number of physiological and psychological benefits. Various pharmacological and non pharmacological regimens to reduce preoperative anxiety have been devised. Much can be done to allay anxiety by explanation and reassurance, but there are many patients who are eager to receive some anxiolysis ${ }^{3-5}$.

Sedatives are agents that are given to relieve tension and anxiety, thereby producing calmness and making it easier for the patient to go to sleep, yet they should not make him actually sleepy ${ }^{2}$. The sedative drugs most commonly employed prior to operation are the benzodiazepines. There are currently more than 20 in the market. Many have active metabolites and several have the same metabolite, desmethyl diazepam in common. Benzodiazepines act at specific receptors in the central nervous system which were first described by Okada in 1977. The receptors are most dense in the cerebral cortex, hypothalamus, cerebellum, corpus striatum and medulla. This regional distribution closely parallels that of the receptors of the inhibitory neurotransmitter gamma amino butyric acid (GABA). The receptors are not identical because the substances do not show competitive binding to the respective receptors sites. Both GABA and benzodiazepines receptors are found on cell surface. Benzodiazepines combine with the receptors and as a result change the effect of GABA on chloride channels, thus allowing chloride ions to enter the cell. This causes an increase in the neurons resting membrane potential making it refractory to any excitatory impulse. By enhancing the effects of GABA in this way, benzodiazepines inhibit certain pathways in the central nervous system ${ }^{3,5,6}$.

Pharmacodynamically the benzodiazepines are qualitatively identical and the differences between them are due to differences in affinity (potency) and to their different pharmacokinetic properties. The success of the benzodiazepines as therapeutic agents, accompanied by the virtual disappearance of the barbiturates, is due to their efficacy as anxiolytic, hypnotic and anticonvulsant, together with their flat log dose-response curve, which gives a much greater safety margin ${ }^{3,7,8}$.

Diazepam is a long acting benzodiazepam which is widely used by the anaesthesiologist for sedation, premedication, induction and even as sole anaesthetic agent. It is poorly soluble in water and the solvent vehicle for parenteral diazepam contains several organic solvents. After oral administration, diazepam is rapidly and completely absorbed, peak blood concentration being achieved within 2 hours of administration. The metabolism of diazepam is slow and elimination half life of 20-40 hours has been reported. Its elimination is reduced in patients with cirrhosis. Diazepam is metabolized in the liver to the major metabolic product desmethyldiazepam, which has pharmacological activity and is metabolized even more slowly than diazepam. Cimetidine inhibits the metabolism of diazepam. Diazepam is extensively bound to plasma proteins (96$98 \%)^{2,3,9,10}$.

Lorazepam is an intermediate acting benzodiazepine which is 4 times more potent than diazepam. It is well absorbed orally, peak plasma concentration being achieved within 3 hours of an oral dose. Systemic availability after oral administration is good (80-93\%). Lorazepam is extensively bound to plasma protein, with a free unbound fraction of $8-12 \%$. The elimination half life of lorazepam is about 10-14 hours. It is conjugated in the liver to the pharmacologically inactive glucuronide, which is then excreted in the urine. The elimination half life of lorazepam is unaffected by cirrhosis and cimetidine does not inhibit its metabolism ${ }^{2,3}$.

In this study both diazepam and lorazepam have been used as anxiolytic sedative night before operation. It has been found that both the drugs have good anxiolytic effect, but the level of anxiolysis and sedation were found more with lorazepam. Previous studies also support this findings ${ }^{4,7,9}$. Other studies showed similar results but in those cases both the drugs were used as premedicants either in oral route or intra-muscularly 2 hours before operation ${ }^{11,12}$. Lorazepam produced significantly more drowsiness than diazepam in the morning of operation day, which was beneficial for induction of anaesthesia and preparation for regional block. Previous studies by Sinha also supports this finding but the greater degree of somnolence and significantly impaired psychomotor function after operation was not advantageous in minor surgical procedures where early discharge after operation is preferred $^{5,8,12}$.

Other side effects like nausea, vertigo were found in some patients in both diazepam and lorazepam groups in which female patients suffered mostly, which might be an individual variation. Previous studies found the incidence of nausea, vomiting in both groups were small and similar and there was more restlessness and dizziness after diazepam in the early recovery period ${ }^{10,12}$. Both the drugs had no significant effect on haemodynamic parameters which is also supported by previous studies $^{10,12}$.

\section{Conclusion}

Patients suffer from anxiety before operation, which should be relieved to get better outcome. In this study, lorazepam produced good sedation and anxiolysis, with no adverse haemodynamic effects. It was associated with hangover effect in a significant number of patients which 
was an advantage for anaesthesiologist. Some other minor side effects e.g nausea, vertigo were observed in both the groups but female patients were more susceptible. On the other hand the quality of sleep and anxiolysis with diazepam was not as good as lorazepam. So, we suggest that lorazepam may be a better choice as anxiolytic sedative night before operation.

\section{References}

1. Serin SK, Lahoti D, Saxena SP, et al. Prevalence, Classification and Vickers MD, Morgan M, Spencer PSJ, Read MS. Drugs in anaesthetic and intensive care practice. 8th ed. London: Butterworth Heinemann; 1999. p.98-107.

2. Wood M, Wood AJJ. Drugs and anaesthesia.2nd ed. London: Williams and Wilkins; 1999. p.196-205.

3. Saari TI, Uusi-Oukari M, Ahonen J, Olkkola KT. Enhancement of GABAergic activity: Neuropharmacological effects of benzodiazepines and therapeutic use in anesthesiology. Pharmacol Rev March 2011; 63: 243-267.

4. Park JS, Lee SM, Yim JJ, at el. Impact of lorazepam on patient satisfaction after flexible bronchoscopy. Am J Respir Crit Care Med 2011; 183: 23-5.
5. Brick N. Premedication for anxiety in adults day surgery patients. AORN J 2010; 92(1): 101-2.

6. Weitz G, Homann N, von Jagow DC, Wellhoner P, Sauer A, Ludwig D. Premedication with orally administered lorazepam in adults undergoing ERCP: a randomized double-blind study. Gastrointest Endosc 2007;66(3): 450-6.

7. Ciccozzi A, Marinangeli F, Colangeli A, et al. Anxiolysis and postoperative pain in patients undergoing spinal anesthesia for abdominal hysterectomy.Minerva Anesthesiol 2007; 73(7-8): 387-93.

8. Sinha PK, Ambesh SP. Pre-operative psychosis following oral lorazepam. Anaesthesia 2003;58(10):1036.

9. McCall JE, Fischer CG, Warden G, et al. Lorazepam given the night before surgery reduces preoperative anxiety in children undergoing reconstructive burn surgery. J Burn Care Rehabil 1999; 20(2): 151-4.

10. Francois M, Francis L, Michel L. A randomized, double-blind, placebo-controlled study of lorazepam as premedication for bronchoscopy. CHEST 1996; 109: 1195-98.

11. Pamela MS, Brian PK, Davy CHC, Joel K, Alan NS. Comparison of lorazepam alone vs lorazepam, morphine, and perphenazine for cardiac premedication. Can J Anaesth 1997; 44: 146-153.

12. Male CG, Johnson HD. Oral benzodiazepine premedication in minor gynaecological surgery. Br J Anaesth 1984;56(5): 499-507. 